\title{
Photoinduced Transformation of Carbon Monoxide in Aqueous Solution
}

\author{
Hyoung Ryun Park and Nikola Getoff* \\ Institute for Theoretical Chemistry and Radiation Chemistry, \\ The University of Vienna, and Ludwig Boltzmann Institute for Radiation Chemistry, \\ both Währingerstr. 38, A-1090 Wien, Austria
}

Z. Naturforsch. 43a, 430-434 (1988); received February 16, 1988

\begin{abstract}
The photoinduced conversion of $\mathrm{CO}$ in aqueous solution under the influence of vacuum-uv radiation at $\lambda=185 \mathrm{~nm}$ has been investigated at $\mathrm{pH}$ values ranging from 2 to 13 . Formaldehyde, glyoxal, carboxylic acids and small amounts of glycol were determined as final products. Initial quantum yields for product formation have been determined. A probable reaction mechanism is presented.
\end{abstract}

\section{Introduction}

It has been shown previously that the action of gamma-radiation on aqueous carbon monoxide leads to the formation of formic acid, formaldehyde and glycol [1]. If suitable organic acceptors are present, incorporation of $\mathrm{CO}$ as a carbonyl group can be achieved in aqueous solutions [2-5] as well as in n-alkanes [6]. Thereby $\mathrm{CHO}$ radical and its hydrated counterpart, $\dot{\mathrm{C}} \mathrm{H}(\mathrm{OH})_{2}$, have been postulated as intermediates in the reduction and carbonylation processes. The existence of the $\mathrm{CHO}$ radicals has been proved by ESR spectroscopy [7]. On the other hand, the reaction of $\mathrm{CO}$ with $\mathrm{OH}$ resulting in $\mathrm{COOH}$ or $\mathrm{HCOO}$ radicals has been demonstrated by pulse radiolysis [8]. Further investigations have shown that incorporation of $\mathrm{CO}$ in aqueous methanol using vacuum-uv radiation at $185 \mathrm{~nm}$ [9] or $123.6 \mathrm{~nm}$ [10] is also possible.

The present work was undertaken in order to investigate the possibility of the photoinduced conversion of aqueous carbon monoxide in the absence of organic acceptors. Quantum yields for product formation have been measured at $\mathrm{pH}$ values ranging from 2 to 13 , and a probable reaction mechanism is presented to explain the results.

* To whom the correspondence should be send.

Reprint requests to Prof. Dr. N. Getoff, Institut für Theoretische Chemie und Strahlenchemie, Universität Wien, Währingerstraße 38, A-1090 Wien/Österreich.

\section{Experimental}

High purity CO (Messer-Griesheim, Austria), p.a. grade chemicals (Merck) and four times distilled water were used for preparation of the solutions. Irradiation of aqueous carbon monoxide $\left(1 \times 10^{-3} \mathrm{~mol} \mathrm{dm}^{-3} \mathrm{CO}\right)$ was performed at $20 \pm 1{ }^{\circ} \mathrm{C}$ in a temperaturecontrolled vessel with $4 \pi$-geometry [11,12]. The $185 \mathrm{~nm}$ line of a low-pressure $\mathrm{Hg}$ lamp (Hanau TNN $15 / 32$ ) was used for the photolysis of water. For adjustment of the pH, p.a. $\mathrm{HClO}_{4}$ or p.a. $\mathrm{NaOH}$ were applied. All solutes used were transparent for the simultaneously emitted uv-light at $254 \mathrm{~nm}$. Actinometry for the $185 \mathrm{~nm}$ line was carried out using $5 \mathrm{~mol} \mathrm{dm}^{-3}$ ethanol with $Q\left(\mathrm{H}_{2}\right)=0.40$ [13]. The integral photon flux at $185 \mathrm{~nm}$ was found to be $I_{0}=8 \times 10^{16}$ quanta $\mathrm{ml}^{-1} \min ^{-1}$

Formaldehyde was determined by spectrophotometry using the method of Hantzsch [14], whereby the reagent yields diacetyldihydrolutidine, whose absorption is monitored at $412 \mathrm{~m}\left(\varepsilon=8000 \mathrm{dm}^{3} \mathrm{~mol}^{-1}\right.$ $\mathrm{cm}^{-1}$ ). The presence of glyoxal does not interfere the measurement. Glyoxal was also determined spectrophotometrically, by means of 2,4-dinitrophenylhydrazine as the reagent $\left(\lambda=575 \mathrm{~nm}, \varepsilon=2160 \mathrm{dm}^{3}\right.$ $\left.\mathrm{mol}^{-1} \mathrm{~cm}^{-1}\right)[5,15]$. The total yield of carboxylic acids formed was measured by differential titration with $\mathrm{NaOH}$ at pH-values below 7 and with $\mathrm{HCl}$ at higher $\mathrm{pH}$-values. The identification of the formic, oxalic and glyoxalic acids was performed by paper chromatography [16]. 


\section{Results and Discussion}

The action of vacuum-uv-light on water results in its photolysis into $\mathrm{H}$ and $\mathrm{OH}$ radicals $[11,12,17]$ and to a smaller extent in formation of hydrated electrons, $\mathrm{e}_{\mathrm{aq}}^{-}[11,12]$ :

$$
\begin{aligned}
& \mathrm{H}_{2} \mathrm{O} \rightarrow \mathrm{H}_{2} \mathrm{O}^{*} \rightarrow \mathrm{H}+\mathrm{OH}, \\
& \mathrm{H}_{2} \mathrm{O}^{*}+\mathrm{H}_{2} \mathrm{O}^{*} \rightarrow \mathrm{H}_{2} \mathrm{O}^{* *}+\mathrm{H}_{2} \mathrm{O}, \\
& \mathrm{H}_{2} \mathrm{O}^{* *} \rightarrow \mathrm{e}_{\mathrm{aq}}^{-}+\mathrm{H}_{\mathrm{aq}}^{+} \text {(autoionization). }
\end{aligned}
$$

The quantum yields $(Q)$ at $185 \mathrm{~nm}$ are: $Q(\mathrm{H})=$ $Q(\mathrm{OH})=0.33$ and $Q\left(\mathrm{e}_{\mathrm{aq}}^{-}\right) \leq 0.03[11]$. In acid solution, $\mathrm{e}_{\mathrm{aq}}^{-}$are converted into $\mathrm{H}$ atoms, whereas in alkaline medium the opposite process takes place:

$$
\begin{aligned}
\mathrm{e}_{\mathrm{aq}}^{-}+\mathrm{H}_{\mathrm{aq}}^{-} & \rightarrow \mathrm{H}\left(k=2.3 \times 10^{10} \mathrm{dm}^{3} \mathrm{~mol}^{-1} \mathrm{~s}^{-1}[18]\right), \\
\mathrm{H}+\mathrm{OH}_{\mathrm{aq}}^{-} & \rightarrow \mathrm{e}_{\mathrm{aq}}^{-}\left(k=1.8 \times 10^{7} \mathrm{dm}^{3} \mathrm{~mol}^{-1} \mathrm{~s}^{-1}[19]\right) .
\end{aligned}
$$

The primary products of water photolysis $(\mathrm{OH}, \mathrm{H}$, and $\mathrm{e}_{\mathrm{aq}}^{-}$) are subsequently reacting with $\mathrm{CO}$ to produce secondary radicals and final photoproducts. As will be discussed below, the main products to be expected are formaldehyde, glyoxal and carboxylic acids.

The dependence of the formaldehyde yield in aqueous solutions saturated with $\mathrm{CO}\left(10^{-3} \mathrm{~mol} \mathrm{dm}^{-3}\right)$ on the absorbed vuv-dose at $\mathrm{pH} 2$ and 7 is shown in Figure 1. The initial quantum yield $\left(Q_{\mathrm{i}}\right)$ is considerably higher at $\mathrm{pH} 2$ than at $\mathrm{pH}$ 7. The saturation like behaviour at higher doses indicates the occurrence of back reactions.

The yield-dose curves for glyoxal formed under the same experimental conditions are presented in Figure 2.

The total yield of carboxylic acids (formic, oxalic and glyoxalic acid) as determined at $\mathrm{pH} 7$ and 12 is presented in Fig. 3 as a function of vuv-dose. The acids yield at $\mathrm{pH}=12$ is markedly higher as compared to the neutral one.

The yields of the final products (formaldehyde, glyoxal and carboxylic acids) are presented in Fig. 4 as a function of $\mathrm{pH}$. The initial quantum yields $\left(Q_{\mathrm{i}}\right)$ of the same products are given in the Table inserted in Figure 4. The most conspicuous feature is the increase of the carboxlic acids yield at $\mathrm{pH}>10$; their total quantum yield is exceeding unity at $\mathrm{pH} 13$.

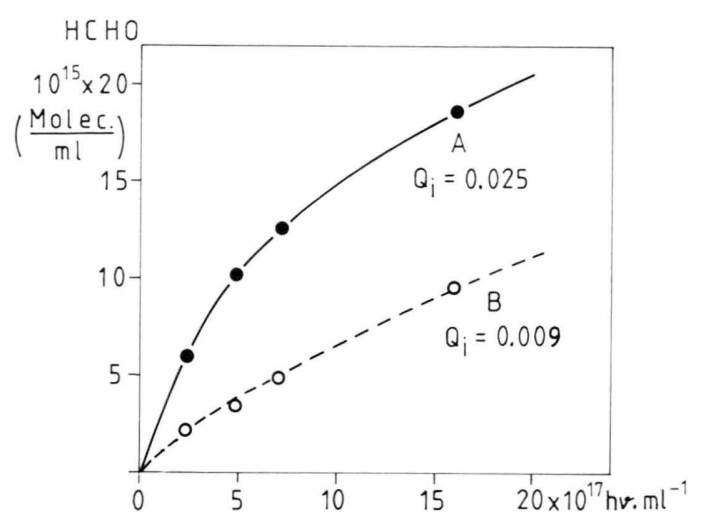

Fig. 1. Formation of formaldehyde at $\mathrm{pH}=2(\mathrm{~A})$ and 7 (B) by reduction of $\mathrm{CO}$ in aqueous solution as a function of u.v.-dose at $20 \pm 1^{\circ} \mathrm{C}$.

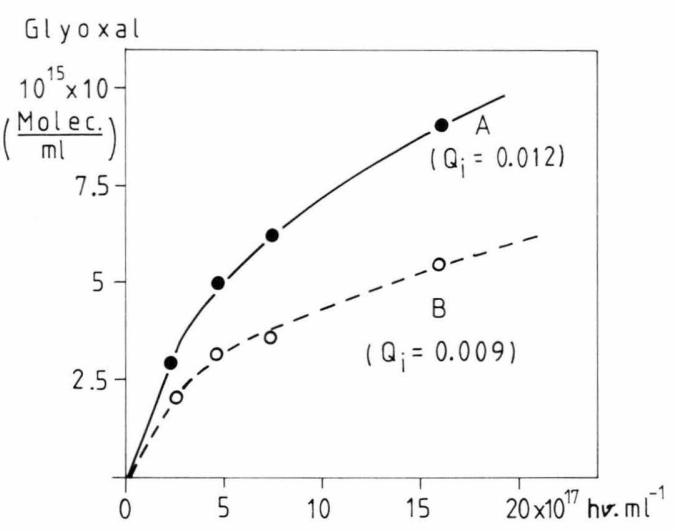

Fig. 2. Formation of glyoxal at $\mathrm{pH}=2(\mathrm{~A})$ and 7 (B) by reduction of $\mathrm{CO}$ in aqueous solution as a function of u.v.-dose at $20 \pm 1{ }^{\circ} \mathrm{C}$.

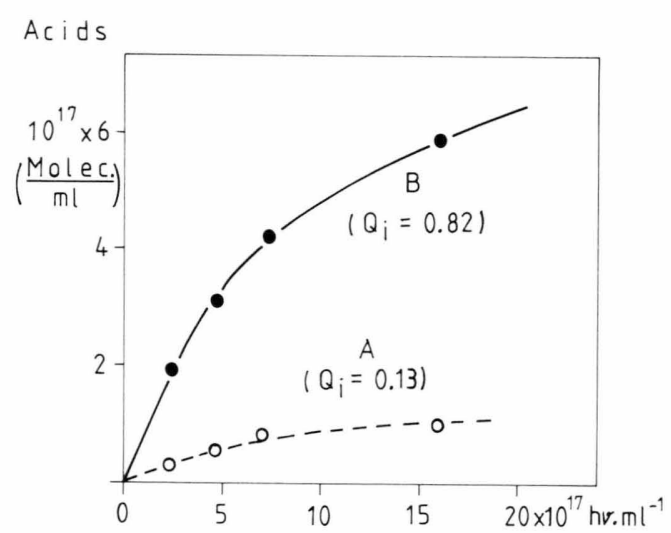

Fig. 3. Total yield of carboxylic acids produced from $\mathrm{CO}$ in aqueous solution at $20 \pm 1{ }^{\circ} \mathrm{C}$ as a function of u.v.-dose at $\mathrm{pH}=7(\mathrm{~A})$ and $12(\mathrm{~B})$. 


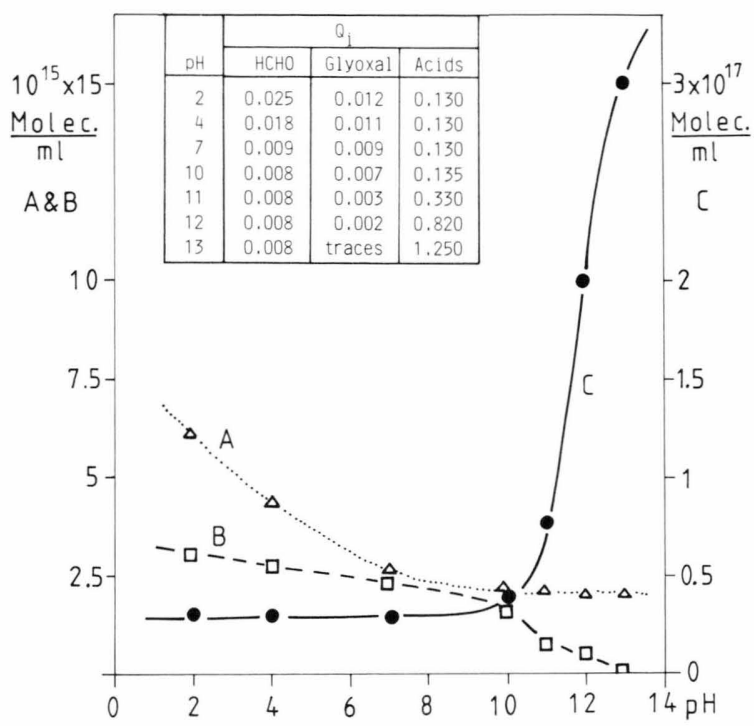

Fig. 4. pH-dependence of the photoinduced formation of aldehyde (A), glyoxal (B) and carboxylic acids (C) in aqueous solution at $20 \pm 1{ }^{\circ} \mathrm{C}$. Applied u.v.-dose: $I=2.4 \times 10^{17} \mathrm{~h} v$. ml of $\lambda=184.9 \mathrm{~nm}$. Insert: Initial quantum yields $\left(Q_{\dot{i}}\right)$ of the products.

\section{A) Acid and Neutral Solutions}

The following reactions are expected to take place in acid and neutral media:

$$
\begin{aligned}
\mathrm{CO}+\mathrm{H} \longrightarrow & \mathrm{HCO} \\
& \left(k=3.8 \times 10^{8} \mathrm{dm}^{3} \mathrm{~mol}^{-1} \mathrm{~s}^{-1}[9]\right), \\
2 \mathrm{HCO} \longrightarrow & \mathrm{CO}+\mathrm{HCHO} \text { (formaldehyde) } \\
\longrightarrow & (\mathrm{HCO})_{2} \text { (glyoxal) } \\
\mathrm{CO}+\mathrm{OH} \longrightarrow & \mathrm{COOH} \\
& \left(k=8.3 \times 10^{8} \mathrm{dm}^{3} \mathrm{~mol}^{-1} \mathrm{~s}^{-1}[1]\right), \\
2 \mathrm{COOH} \longrightarrow & \mathrm{CO}_{2}+\mathrm{HCOOH}(\text { formic acid) } \\
\longrightarrow & \left(\mathrm{COOH}_{2}(\mathrm{oxalic} \text { acid) }\right. \\
& \left(2 \mathrm{k}=2.0 \times 10^{9} \mathrm{dm}^{3} \mathrm{~mol}^{-1} \mathrm{~s}^{-1}[20]\right), \\
\rightleftharpoons & \mathrm{COO}^{-}+\mathrm{H}^{+} \\
& \left(\mathrm{pK}_{\mathrm{a}}=2.8[21] ; 2.7[22]\right) .
\end{aligned}
$$

Hence, in weak acid solutions $(\mathrm{pH} \geq 4.8)$ only oxalate is formed:

$$
\begin{aligned}
2 \mathrm{COO}^{-} \rightarrow & \left(\mathrm{COO}^{-}\right)_{2} \\
& \left(2 k=1.26 \times 10^{9} \mathrm{dm}^{3} \mathrm{~mol}^{-1} \mathrm{~s}^{-1}[20]\right) \\
& \left(2 k=1 \times 10^{9} \mathrm{dm}^{3} \mathrm{~mol}^{-1} \mathrm{~s}^{-1}[8]\right) .
\end{aligned}
$$

In addition to the formic and oxalic acids, glyoxalic acid is also produced by combination of $\mathrm{HCO}$ and
$\mathrm{COOH}\left(\right.$ or $\mathrm{CO}_{2}^{-}$) transients, e.g.:

$\mathrm{HCO}+\mathrm{COOH} \rightarrow \mathrm{HCO} \cdot \mathrm{COOH}$ (glyoxalic acid).

Further, combination of the present free radicals is also very likely, e.g.

$$
\begin{aligned}
& \mathrm{HCO}+\mathrm{H} \rightarrow \mathrm{HCHO}, \\
& \mathrm{HCO}+\mathrm{OH} \rightarrow \mathrm{HCOOH}, \\
& \mathrm{COOH}+\mathrm{H} \rightarrow \mathrm{HCOOH}, \\
& \mathrm{COOH}+\mathrm{OH} \rightarrow \mathrm{CO}_{2}+\mathrm{H}_{2} \mathrm{O} .
\end{aligned}
$$

At higher doses, primary and secondary radicals will attack the final products with increasing probability. These reactions will in part lead to products different from those mentioned before, e.g.

$$
\begin{aligned}
& \mathrm{HCHO}+\mathrm{H} \longrightarrow \mathrm{HC} \mathrm{CO}+\mathrm{H}_{2} \\
& \left(k=5 \times 10^{6} \mathrm{dm}^{3} \mathrm{~mol}^{-1} \mathrm{~s}^{-1}[23]\right), \\
& \mathrm{HCHO}+\mathrm{OH} \longrightarrow \mathrm{HC} \dot{\mathrm{CO}}+\mathrm{H}_{2} \mathrm{O} \\
& \left(k=2 \times 10^{9} \mathrm{dm}^{3} \mathrm{~mol}^{-1} \mathrm{~s}^{-1}[24]\right), \\
& \mathrm{HCHO}+\dot{\mathrm{COOH}} \longrightarrow \dot{\mathrm{C}} \mathrm{H}_{2} \mathrm{OH}+\mathrm{CO}_{2}, \quad \text { (19a) } \\
& \rightarrow \mathrm{HCO}+\mathrm{HCOOH} \\
& 2 \dot{\mathrm{C}} \mathrm{H}_{2} \mathrm{OH} \\
& \rightarrow \mathrm{HCHO}+\mathrm{CH}_{3} \mathrm{OH} \\
& \text { (methanol) } \\
& \longrightarrow\left(\mathrm{CH}_{2} \mathrm{OH}\right)_{2} \text { (glycol) } \\
& 2 k=1.9 \times 10^{9} \mathrm{dm}^{3} \mathrm{~mol}^{-1} \mathrm{~s}^{-1}[25] \text {. }
\end{aligned}
$$

In analogy to HCHO (reactions (17) and (18)) also glyoxal and carboxylic acids can be decomposed by attack of $\mathrm{H}, \mathrm{OH}$ and other intermediated occuring during the irradiation. Small amounts of glycol were actually detected among the products. Reactions of this type will contribute to the saturation-like behaviour observed in Figures 1-3.

The formation of hydrogen gas was detected by gaschromatography, but its yield was not determined at present.

Figure 4 shows that the major part of photoproducts is present as carboxylic acids at all $\mathrm{pH}$ 's. This may be explained, at least in part, by assuming that the HCO radicals are available in hydrated form $[5,26,27]$ :

$$
\mathrm{HCO}+\mathrm{H}_{2} \mathrm{O} \rightleftharpoons \mathrm{HC}(\mathrm{OH})_{2} .
$$

In a related study on photoinduced degradation of formaldehyde [28] it has been shown that the hydrated formyl radicals, $\mathrm{HC}(\mathrm{OH})_{2}$, tend to disproportionate to formic acid and hydrated formaldehyde, 
whereas hydrated glyoxal does not arise:

$\begin{aligned} 2 \dot{\mathrm{C}} \mathrm{H}(\mathrm{OH})_{2} \underset{ }{\longrightarrow} & \mathrm{HCOOH}+\mathrm{CH}_{2}(\mathrm{OH})_{2} \\ & \left(\mathrm{CH}(\mathrm{OH})_{2}\right)_{2} .\end{aligned}$

Finally, reaction (6) being somewhat slower than reaction (8), secondary $\mathrm{H}$ atom reactions will be more efficient than $\mathrm{OH}$ reactions in competing with attack on $\mathrm{CO}$.

In neutral and acid solutions, the total yield of final products is smaller than the yield for water splitting [11]. This may reflect a competition between in-cage recombination of $\mathrm{H}$ and $\mathrm{OH}$ and reaction with $\mathrm{CO}$. Enhanced formaldehyde and glyoxal yields in acid medium probably reflect reaction (4); in neutral solution, attack of $\mathrm{e}_{\mathrm{aq}}^{-}$on $\mathrm{CO}$ should give rise to carboxylic acids, as discussed below.

\section{B) Alkaline Solutions}

The total yield of formic, oxalic and glyoxalic acid formed by the photoinduced conversion of $\mathrm{CO}$ in basic solution $(\mathrm{pH}=12)$ as a function of the vuv-dose is presented as curve (B) in Figure 3. In this case the total yield of carboxylic acids is much higher compared to that one observed at $\mathrm{pH}=7$.

In addition to water photolysis, absorption of $185 \mathrm{~nm}$ light by $\mathrm{OH}_{\mathrm{aq}}^{-}$ions $\left(\varepsilon=3600 \mathrm{dm}^{3} \mathrm{~mol}^{-1} \mathrm{~cm}^{-1}\right.$ [29]) must be taken into account in alkaline solutions. However, this process will essentially lead to the same primary photoproducts as water photolysis by virtue of

$$
\mathrm{OH}_{\mathrm{aq}}^{-}-m \rightarrow\left(\mathrm{OH}_{\mathrm{aq}}^{-}\right)^{*} \rightarrow \mathrm{OH}+\mathrm{e}_{\mathrm{aq}}^{-}
$$

and the fact that reaction (5) will tend to convert primary $\mathrm{H}$ atoms from water photolysis into $\mathrm{e}_{\mathrm{aq}}^{-}$.

Further to be taken into account is the dissociation of $\mathrm{OH}$ radicals:

$\begin{aligned} \mathrm{OH} & \rightleftharpoons \dot{\mathrm{O}}_{\mathrm{aq}}^{-}+\mathrm{H}^{+}(p K=11.9[30]), \\ \mathrm{CO}+\dot{\mathrm{O}}_{\mathrm{aq}}^{-} & \rightarrow \mathrm{COO}^{-}\left(k=3 \times 10^{8} \mathrm{dm}^{3} \mathrm{~mol}^{-1} \mathrm{~s}^{-1}[25]\right) .\end{aligned}$

As mentioned before (Fig. 3 and 4) the total yield of carboxylic acids increases strongly with increasing $\mathrm{pH}$. The glyoxal yield decreases correspondingly, whereas the formaldehyde yield remains constant. A comparable increase in alkaline medium was found for the formation of formic acid in the $\gamma$-radiolysis of aqueous $\mathrm{CO}$ [1]. The magnitude of the yields indicates that a chain reaction must be involved.

As mentioned above (reaction 5), the $\mathrm{H}$-atoms are converted into $\mathrm{e}_{\mathrm{aq}}^{-}$in alkaline soltuions. Reaction (23) is also responsible for the increase of $\mathrm{e}_{\mathrm{aq}}^{-}$yield, hence $\mathrm{CO}+\mathrm{e}_{\mathrm{aq}}^{-} \rightarrow \dot{\mathrm{CO}_{\mathrm{aq}}^{-}}\left(k=1 \times 10^{9} \mathrm{dm}^{3} \mathrm{~mol}^{-1} \mathrm{~s}^{-1}[4]\right)$.

The $\dot{\mathrm{CO}_{\text {aq }}^{-}}$transients are identical with $\mathrm{HCOOH}^{-}$ species, which can initiate a chain reaction with $\mathrm{OH}_{\mathrm{aq}}^{-}$ $[1,5]$, namely

$$
\begin{aligned}
& \mathrm{HCOOH}^{-}+\mathrm{OH}_{\mathrm{aq}}^{-} \rightarrow \mathrm{HCOO}^{-}+\mathrm{e}_{\mathrm{aq}}^{-}, \\
& \mathrm{HCOO}^{-}+\mathrm{OH} \rightarrow \mathrm{COO}^{-}+\mathrm{H}_{2} \mathrm{O} \\
& \left(k=2.5 \times 10^{9} \mathrm{dm}^{-1} \mathrm{~mol}^{-1} \mathrm{~s}^{-1}[31]\right) .
\end{aligned}
$$

The $\mathrm{COO}^{-}$species lead to the formation of oxalate (reaction 11) and glyoxalic acid

$$
\mathrm{HCO}+\mathrm{COO}^{-} \rightarrow \mathrm{HCO} \mathrm{COO}^{-} .
$$

Nothing is known about the reaction behaviour of $\mathrm{CO}_{\mathrm{aq}}^{-}$, although their participation in the chain process was suggested previously [1]. A clue can be seen in the decrease in glyoxal formation at high $\mathrm{pH}$ values (Fig. 4), which shows that reaction (7b) is inefficient under these conditions. Reaction (7a) seems to take place since formaldehyde is found up to $\mathrm{pH} 13$, but it might be assumed that its rate constant is much smaller than in neutral solution.

Depending on the $\mathrm{pH}$ of the solution the following equilibrium is conceivable:

$\mathrm{HCOOH}^{-} \stackrel{-\mathrm{H}_{2} \mathrm{O}}{\rightleftharpoons} \dot{\mathrm{CO}^{-}} \stackrel{+\mathrm{H}^{+}}{\rightleftharpoons} \dot{\mathrm{C}} \mathrm{HO} \stackrel{+\mathrm{H}_{2} \mathrm{O}}{\rightleftharpoons} \dot{\mathrm{C}} \mathrm{H}(\mathrm{OH})_{2}$.

This postulation could contribute to a better understanding of the obtained product yields.

\section{Conclusion}

It has been shown for the first time that carbon monoxide in aqueous solution can be converted into various simple organic compounds by irradiation with light at $185 \mathrm{~nm}$. The product yields show a specific $\mathrm{pH}$ dependence, which can be explained by the properties of the photoproduced primary species. In alkaline solutions, carboxylic acids are formed by a chain reaction mechanism. 
[1] Y. Raef and A. J. Swallow, Trans. Faraday Soc. 59, 1631 (1963).

[2] J. Holian, G. Scholes, and J. J. Weiss, Nature 191, 1386 (1961).

[3] N. Getoff and D. Seitner, Z. Phys. Chem. (NF) 51, 27 (1966).

[4] D. Seitner and N. Getoff, Z. Phys. Chem. 66, 22 (1969).

[5] D. Seitner and N. Getoff, Monatsh. Chem. 100, 1868 (1969).

[6] E. P. Kalyazin and N. M. Baranova, Neftekhimiya (russ.) 4, 275 (1964).

[7] R. Marz and C. Chachaty, J. Chim. Phys. 58, 527 (1961).

[8] J. P. Keene, Y. Raef, and A. J. Swallow, p. 99 in: Pulse Radiolysis, eds. M. Ebert, J. P. Keene, A. J. Swallow, and J. H. Baxendale, Academic Press, London 1965.

[9] N. Getoff and H. P. Lehmann, Int. J. Radiat. Phys Chem. 2, 91 (1970).

[10] W. Zich and N. Getoff, Monatsh. Chem. 100, 1745 (1969).

11] N. Getoff, Monatsh. Chem. 99, 136 (1968)

[12] N. Getoff and G. O. Schenck, Photochem. Photophys. 8, 167 (1968)

[13] C. von Sonntag and H. P. Schuchmann, Adv. Photochem. 10, 59 (1977).

[14] T. Nasch, Biochem. J. 55, 418 (1958).

[15] T. Banks, C. Vaughn, and L. Marshall, Analyt. Chem. 27, 1348 (1955)

[16] R. D. Hartley and G. I. Lawson, J. Chromatog. 7, 69 (1962).
[17] F. S. Dainton and P. Fowles, Proceed. Roy. Chem. Soc. A 287, 295 (1965).

[18] L. M. Dorfman and I. A. Taub, J. Amer. Chem. Soc. 85, 2370 (1963).

[19] M. S. Matheson and J. Rabani, J. Phys. Chem. 69, 1324 (1965).

[20] N. Getoff and F. Schwörer, unpubl. data.

[21] F. Gütlbauer and N. Getoff, Z. Phys. Chem. (NF) 5, 225 (1966).

[22] D. Jez and N. Getoff, unpublished results.

[23] J. H. Baxendale and D. Smithies, Z. Phys. Chem. (NF) 7, 242 (1956).

[24] E. J. Hart, J. K. Thomas, and S. Gordon, Radiat. Res. Suppl. 4, 74 (1964).

[25] N. Getoff, unpublished results.

[26] J. Walker, Formaldehyde, 3 ed. Reinhold Pub. Comp., New York 1964.

[27] R. Bieber and G. Trümpler, Helv. Chim. Acta 30, 1860 (1947).

[28] H. R. Park and N. Getoff, J. Photochem. Photob., in print.

[29] F. S. Dainton and P. Fowles, Proc. Roy. Chem. Soc. A-287, 312 (1965).

[30] J. W. T. Spinks and R. J. Woods, An Introduction to Radiation Chemistry, John Wiley \& Sons, New York 1976.

[31] J. K. Thomas, Faraday Soc. 61, 702 (1965). 